\title{
Effect of foliar application of Trichoderma on the quality of tomato fruits grown in different hydroponic substrates
}

\author{
Rogelio Enrique Palacios-Torres, Aldo Guadalupe Bustamante-Ortiz, \\ Luis Alberto Prieto-Baeza, Hipólito Hernández-Hernández*, \\ Ana Rosa Ramírez-Seañez, José Antonio Yam-Tzec, Gabriela Díaz-Félix
}

Ingeniería Agrícola Tropical, Universidad del Papaloapan Av. Ferrocarril s/n, Ciudad Universitaria, Loma Bonita, Oaxaca, CP 68400, México

\begin{abstract}
The quality of tomato fruits is influenced by preharvest factors. Trichoderma are considered biostimulants with potential to improve growth and development in plants, as well as the quality of the fruits. The objective of this study was to evaluate the effect of foliar application of Trichoderma on the quality of tomato fruits at different cluster levels on the same plant in two commercial hybrids using three different substrates in a greenhouse. Six foliar applications of a liquid biological preparation of Trichoderma were performed at a dose of $4 \mathrm{~mL} \mathrm{~L}^{-1}$ every 15 days after transplanting. The results show that the foliar application of Trichoderma increased the ratio of soluble solids to titratable acidity of the fruits at different cluster levels, which was mainly due to the decrease in acidity rather than the increase in soluble solids. The decrease in titratable acidity is in accordance with the increase in the $\mathrm{pH}$ of the fruits. Trichoderma have a positive effect on titratable acidity, $\mathrm{pH}$ and electrical conductivity of fruits. In the Cid hybrid grown in the tezontle substrate, the application of Trichoderma increased the ratio of total soluble solids to titratable acidity. At the same time, sand increased the percentage of juice in the fruits. Foliar application of Trichoderma increases the quality of tomato fruits, and as such, should be considered as a crop management option.
\end{abstract}

Key words: cluster level, inorganic substrates, soluble solids, titratable acidity

\section{INTRODUCTION}

Tomato is the second most important vegetable crop worldwide after potato (FAOSTAT, 2015). This vegetable is generally consumed fresh. The quality of tomato fruits, like that of other vegetables, is defined mostly by direct consumer perception based on fruit size, weight, colour, flavour, aroma, and texture (Oltman et al., 2014; Bertin and Génard, 2018). Colour is the most important external characteristic to consumers, followed by juiciness, size, the presence of seeds, and firmness
(Oltman et al., 2014). The internal quality of fruits is closely related to flavour, which is the result of a complex interaction among different chemical components (sugars, organic acids, salts, amino acids and volatiles) of which the total soluble solids content (TSS), titratable acidity (TA), and their reciprocal ratio give an important, but not exclusive, contribution to tomato flavour (Causse, 2002; Valero and Serrano, 2010).

Both the external and internal quality of the tomato fruit is influenced by preharvest factors, such as crop management practices, cultivar

*Corresponding author. 
diversity, and environmental conditions (Davies and Hobson, 1981; Bertin and Génard, 2018). Temperature, relative humidity, and solar radiation are the main environmental factors that affect fruit quality (Biais et al., 2014). Tomato crops present a large variety of local cultivars that are characterized by their organoleptic properties and the functional quality of their fruits (Figàs et al., 2015). Physiologists are currently studying fruit quality in relation to genetic, environmental and management interactions in order to develop new crop management strategies and design genotypes adapted to particular conditions (Génard et al., 2015; Bertin and Génard, 2018).

Trichoderma are considered among the main biological control agents against phytopathogenic fungi, in addition to being biostimulants. Application of Trichoderma to plants activates secondary metabolites that help to promote growth, improve nutrient availability, and induce systemic resistance against diseases, mainly phytopathogenic fungi (Pascale et al., 2017). In addition, some studies report that Trichoderma improve the quality of the tomato fruit (Molla et al., 2012; Nzanza et al., 2012). For these reasons, the objective of this study was to evaluate the effect of foliar application of Trichoderma on the quality of tomato fruits from clusters at different levels of the plant in two tomato hybrids grown in three inorganic substrates under greenhouse conditions.

\section{MATERIAL AND METHODS}

\section{Establishment of the experiment}

Tomato plants were established in a polyethylenecovered greenhouse, at $25^{\circ} \mathrm{C}$ and $82 \%$ relative humidity, at the University of Papaloapan, Loma Bonita Campus, Oaxaca, Mexico. Seeds were planted in September 2013 in 200-well polystyrene trays using peat moss as a substrate. Seedlings were transplanted 30 days later at a density of four plants per $\mathrm{m}^{2}$ in 12-L capacity black polyethylene bags $(40 \times 40 \mathrm{~cm})$. A localized irrigation system was used, and Steiner nutritive solution (Steiner, 1961) was applied at different concentrations during watering after transplanting: for the first two weeks at $50 \%$, in the third and fourth week at $75 \%$, and from the fifth week onward at $100 \%$. The plants were pruned to one main stem and eight fruit clusters by day 110 post-transplant.

\section{Description of treatments}

Treatments consisted of three inorganic substrates (river sand, tezontle and tepezil), two hybrids of indeterminate growth saladette tomatoes (Ramsés and Cid) from the Harris Moran company, and the application of Trichoderma (with and without Trichoderma). The tezontle and tepezil substrates are of volcanic origin, reddish and white, respectively. The liquid biological preparation contained Trichoderma asperelloides strain VSL4 (MH370294) and T. koningiopsis strain VSL185 (KU215377), which were isolated and identified by Dr. Vladimir Sánchez López (Universidad del Papaloapan). The conidial suspension (T. asperelloides $+T$. koningiopsis) was adjusted to $1 \times 10^{8}$ conidia of each Trichoderma species per ml. Six foliar applications of a solution of Trichoderma at $4 \mathrm{~mL}$ per litre of water were performed at intervals of 15 days after transplanting the seedlings. A total volume of $60 \mathrm{~mL}$ of the Trichoderma solution per plant was applied during the experiment. The control treatment was foliar application of water. Fruits were sampled from clusters at three different levels of the plant (level 1: clusters 1 and 2; level 2: clusters 4 and 5; level 3: clusters 7 and 8). The fruits were harvested at a maturity stage of 6 on the United States Department of Agriculture scale (more than $90 \%$ of the surface of the tomato red in colour; USDA, 1991).

\section{Analysis of fruit quality}

The quality of the fruits was analyzed at the food laboratory at the University of Papaloapan, Tuxtepec Campus, Oaxaca, Mexico. Mature fruits were harvested and washed with distilled water. The total soluble solids (TSS) content was measured in the juice of six fruits ground with a juicer $\left(\right.$ Moulinex $\left.^{\circledR}\right)$; three drops of the ground juice were placed in a refractometer (HI 96801 Hanna Instruments ${ }^{\circledR}$ ) which was previously calibrated with distilled water. Then, three fruits per level were ground with a juicer (Moulinex ${ }^{\circledR}$ ) to obtain $50 \mathrm{~mL}$ of juice, which was placed into test tubes and centrifuged at $4500 \mathrm{rpm}$ for 20 minutes (Centrifugen Rutina 420 Hetticha $^{\circledR}$ ). The titratable acidity was determined in $10 \mathrm{~mL}$ of the centrifuged juice in a titration flask; phenolphthalein was added, then the mixture was titrated with $\mathrm{NaOH}(0.1 \mathrm{~N})$ and the acidity value was obtained in percent citric acid using the method of the AOAC (2000). The ratio of TSS to TA was calculated. The $\mathrm{pH}$ and electrical conductivity $(\mathrm{mV})$ were measured in the centrifuged juice with a potentiometric $\mathrm{pH}$ meter (Science Med SM-25cw Microprocessor $\mathrm{pH} / \mathrm{mV}$ Meter $\left.^{\circledR}\right)$. The percentage of juice (PJ) was calculated using the following formula: Juice mass / Fruit mass $\times 100$. The colour 
of the fruits was measured with a colorimeter (Hunter Lab Color Flex Mod.124); L, a and b values were taken at opposite zones in the middle of the fruits from 6 fruits per level. Those values were used to calculate the hue angle (HUE) and colour purity (CHROMA) using the formulas proposed by Heredia et al. (2007). HUE $=\tan ^{-1}(\mathrm{~b} / \mathrm{a})$; CHROMA $=\left(a^{2}+b^{2}\right)^{1 / 2}$. Luminosity $(L)$ was obtained directly from the colorimeter.

\section{Statistical analyses}

For to each variable, three replicates per treatment were used in a factorial experiment $(3 \times 2 \times 2)$ in a completely randomized design. Each replicate was obtained from one different plant. The cluster levels were not considered a factor. One-way and two-way analyses of variance were performed for each variable evaluated. To assess the differences between means, the Tukey means test $(p \leq 0.05)$ was used. All statistical analyses were performed with InfoStat software (InfoStat, 2018).

\section{RESULTS AND DISCUSSION}

The foliar application of Trichoderma increased the total soluble solids (TSS) in level 1 clusters and decreased TSS at levels 2 and 3 (Tab. 1). The application of Trichoderma to the Cid hybrid increased TSS by $14 \%$ at level 1; however, it decreased TSS by $6 \%$ in level 3 fruits (Tab. 2). The application of Trichoderma to the Ramsés hybrid negatively affected TSS at all three levels (by 6, 7 , and $9 \%$, respectively). Of the two genotypes, the Cid hybrid had a higher TSS compared to the Ramsés hybrid at levels 1 and 2 (by 22 and 10\%, respectively) with the application of Trichoderma.

The foliar application of Trichoderma increased the TSS content by $12 \%$ at level 1 in the tomato plants planted in the tezontle substrate; in contrast, it decreased the TSS content in the plants established in river sand and tepezil at levels 2 and 3 (by 9 and $13 \%$, respectively). The tezontle-grown fruits had a higher TSS content compared to those grown in river sand at all three cluster levels, with and without Trichoderma application. Molla et al. (2012) report that the application of Trichoderma increases the TSS content of tomato fruits. In this study, it was demonstrated that the effect of Trichoderma on the fruits depended on the cultivar and the level of the fruit cluster, as well as the substrate used. Bertin and Génard (2018) mention that preharvest factors, cultivar, and environment significantly influence tomato fruit quality, as was demonstrated in this study. The use of Trichoderma in the management of tomato crops not only increases the plant's nutrient absorption capacity (López-Bucio et al., 2015), but it may also increase the accumulation of sugars in the fruits (Molla et al., 2012). This may be because the application of Trichoderma improved

Table 1. Effect of foliar application of Trichoderma on total soluble solids ( ${ }^{\circ}$ Brix) at different levels of fruit clusters on the plant

\begin{tabular}{lccc}
\hline Treatment & Level 1 & Level 2 & Level 3 \\
\hline With Trichoderma & ${ }^{* * *} 4.76 \mathrm{a}$ & ${ }^{* *} 4.59 \mathrm{~b}$ & ${ }^{* * *} 5.22 \mathrm{~b}$ \\
Without Trichoderma & $4.57 \mathrm{~b}$ & $4.77 \mathrm{a}$ & $5.64 \mathrm{a}$ \\
\hline
\end{tabular}

ANOVA significance at each level: $* *<0.01, * * *<0.001$. Mean values followed by the same letter within the same column are not significantly different according to the Tukey test at $p \leq 0.05$

Table 2. Effect of interaction between Trichoderma treatment, hybrids, and substrates on total soluble solids content ( ${ }^{\circ}$ Brix) at three fruit cluster levels

\begin{tabular}{|c|c|c|c|c|c|c|}
\hline & \multicolumn{2}{|c|}{ Level 1} & \multicolumn{2}{|c|}{ Level 2} & \multicolumn{2}{|c|}{ Level 3} \\
\hline & With T & No $T$ & With T & No $T$ & With T & No $T$ \\
\hline & \multicolumn{6}{|c|}{ Hybrids $\times$ Trichoderma } \\
\hline Cid & ${ }^{* * *} 5.24 \mathrm{a}$ & $4.58 \mathrm{~b}$ & ${ }^{* *} 4.82 \mathrm{a}$ & $4.84 \mathrm{a}$ & NS5.20 b & $5.55 \mathrm{a}$ \\
\hline \multirow[t]{2}{*}{ Ramsés } & $4.28 \mathrm{c}$ & $4.56 \mathrm{~b}$ & $4.37 \mathrm{~b}$ & $4.70 \mathrm{a}$ & $5.23 \mathrm{~b}$ & $5.73 \mathrm{a}$ \\
\hline & \multicolumn{6}{|c|}{ Substrates $\times$ Trichoderma } \\
\hline River Sand & ${ }^{* * *} 4.38 \mathrm{~cd}$ & $4.27 \mathrm{~d}$ & ${ }^{* *} 4.13 \mathrm{~d}$ & $4.53 \mathrm{c}$ & ${ }^{*} 4.95 \mathrm{de}$ & $5.25 \mathrm{~cd}$ \\
\hline Tepezil & $4.78 \mathrm{~b}$ & $4.87 \mathrm{~b}$ & $4.73 \mathrm{bc}$ & $4.75 \mathrm{bc}$ & $4.88 \mathrm{e}$ & $5.59 \mathrm{bc}$ \\
\hline Tezontle & $5.12 \mathrm{a}$ & $4.57 \mathrm{c}$ & $4.92 \mathrm{ab}$ & $5.03 \mathrm{a}$ & $5.82 \mathrm{ab}$ & $6.08 \mathrm{a}$ \\
\hline
\end{tabular}

ANOVA significance for the two interactions at each level: ${ }^{\text {NS }}$ not significant, $*<0.05, * *<0.01, * * *<0.001$. Mean values followed by the same letter within the same column or row are not significantly different according to the Tukey test at $p \leq 0.05$; With $\mathrm{T}-$ with Trichoderma; No T - without Trichoderma 
Table 3. Effect of foliar application of Trichoderma on titratable acidity (\% citric acid) at different cluster levels of the plant

\begin{tabular}{lccc}
\hline Treatment & Level 1 & Level 2 & Level 3 \\
\hline With Trichoderma & ${ }^{* *} 0.220 \mathrm{~b}$ & ${ }^{\mathrm{Ns}} 0.210 \mathrm{a}$ & $*_{* * *} 0.240 \mathrm{~b}$ \\
Without Trichoderma & $0.240 \mathrm{a}$ & $0.220 \mathrm{a}$ & $0.270 \mathrm{a}$ \\
\hline
\end{tabular}

ANOVA significance at each level: Ns not significant, $* *<0.01, * * *<0.001$. Mean values followed by the same letter within the same column are not significantly different according to the Tukey test at $p \leq 0.05$

Table 4. Effect of interaction between Trichoderma, hybrid, and substrate on titratable acidity (\% citric acid) at three cluster levels

\begin{tabular}{|c|c|c|c|c|c|c|}
\hline & \multicolumn{2}{|c|}{ Level 1} & \multicolumn{2}{|c|}{ Level 2} & \multicolumn{2}{|c|}{ Level 3} \\
\hline & With T & No $T$ & With T & No $T$ & With T & No $T$ \\
\hline & \multicolumn{6}{|c|}{ Hybrids $\times$ Trichoderma } \\
\hline Cid & ${ }^{\mathrm{NS}} 0.219 \mathrm{~b}$ & $0.235 \mathrm{a}$ & ${ }^{\mathrm{NS}} 0.210 \mathrm{a}$ & $0.214 \mathrm{a}$ & ${ }^{\mathrm{NS}} 0.250 \mathrm{~b}$ & $0.280 \mathrm{a}$ \\
\hline \multirow[t]{2}{*}{ Ramsés } & $0.226 \mathrm{ab}$ & $0.239 \mathrm{a}$ & $0.216 \mathrm{a}$ & $0.220 \mathrm{a}$ & $0.223 \mathrm{c}$ & $0.267 \mathrm{ab}$ \\
\hline & \multicolumn{6}{|c|}{ Substrates $\times$ Trichoderma } \\
\hline River sand & ${ }^{*} 0.224 \mathrm{bc}$ & $0.224 \mathrm{bc}$ & ${ }^{\mathrm{NS}} 0.198 \mathrm{~cd}$ & $0.194 \mathrm{~d}$ & ${ }^{* * * *} 0.220 \mathrm{c}$ & $0.243 \mathrm{bc}$ \\
\hline Tepezil & $0.239 \mathrm{ab}$ & $0.258 \mathrm{a}$ & $0.218 \mathrm{bc}$ & $0.217 \mathrm{bc}$ & $0.262 \mathrm{~b}$ & $0.262 \mathrm{~b}$ \\
\hline Tezontle & $0.205 \mathrm{c}$ & $0.228 \mathrm{~b}$ & $0.224 \mathrm{ab}$ & $0.240 \mathrm{a}$ & $0.228 \mathrm{c}$ & $0.316 \mathrm{a}$ \\
\hline
\end{tabular}

ANOVA significance for the two interactions at each level: Ns not significant, $*<0.05, * * *<0.001$. Mean values followed by the same letter within the same column or row are not significantly different according to the Tukey test at $p \leq 0.05$; With $\mathrm{T}-$ with Trichoderma; No T - without Trichoderma

the carbohydrate metabolism and increased the accumulation of starches in the plant (Shoresh and Harman, 2008). This, in turn, could explain the decrease in TSS, since starch molecules have very little effect on the refractive index of tomato juice. Our results are consistent with those reported by Ruiz-Cisneros et al. (2018), who showed that Trichoderma decreased TSS (by 16\%) due to lower carbohydrate hydrolysis.

The foliar application of Trichoderma decreased the titratable acidity (TA) in the fruits from levels 1 and 3 (Tab. 3). The treatment decreased TA in the Cid hybrid at levels 1 and 3 (by 7 and 11\%, respectively) and in the Ramsés hybrid only at level 3 (by 17\%) (Tab. 4). The Cid hybrid had a higher TA at level 3 (by 12\%) with the application of Trichoderma, compared to the Ramsés hybrid. The application of Trichoderma to the plants growing in the tezontle substrate decreased TA at levels 1 and 3 (by 10 and 28\%, respectively). Among the substrates, tezontle contributed to a lower TA than tepezil at levels 1 and 3 with the application of Trichoderma. Without Trichoderma application, the tezontle reduced the TA at level 1; however, it increased TA at levels 2 and 3, compared to tepezil. During the process of maturation, fruits naturally increase their accumulation of sugars and decrease their organic acids (Chen et al., 2012). The acidity decreases progressively as the amount of red and orange pigments increases in tomato fruits (Winsor et al., 1962). In this study, we have shown that the foliar application of Trichoderma decreases the concentration of organic acids (citric acid) at different cluster levels of the two genotypes; this effect could be due to the secondary metabolites produced by the genus Trichoderma (Keswani et al., 2014). In this sense, foliar application of Trichoderma in tomatoes could help improve flavour for the consumption of fresh fruits. In contrast, Ruiz-Cisneros et al. (2018) reported that Trichoderma increased TA (by $21 \%$ ), which may be due to Trichoderma increasing the weight and maturity of tomato fruit. Bal and Altintas (2006) had found no significant differences in TA or TSS.

The foliar application of Trichoderma increased the ratio of total soluble solids to titratable acidity (TSS/TA) at levels 1 and 3 (Tab. 5). The treatment increased TSS/TA in the Cid hybrid (by $22 \%$ ) at level 1 and in the Ramsés hybrid (by 11\%) at level 3 (Tab. 6). The Cid hybrid had a higher TSS/TA ratio with the application of Trichoderma, compared to the Ramsés hybrid (by 14\%) at level 2. The application of Trichoderma to the plants grown in tezontle increased TSS/TA at levels 1 and 3 (by 24 and $34 \%$, respectively). Fruits with a higher TSS/ TA ratio have a better flavour (Tigist et al., 2013). Keswani et al. (2014) mention that the volatile and non-volatile compounds produced by Trichoderma 
Table 5. Effect of Trichoderma on the ratio of total soluble solids to titratable acidity in different clusters of the plant

\begin{tabular}{lrrr}
\hline Treatment & Level 1 & Level 2 & Level 3 \\
\hline With Trichoderma & ${ }^{* * *} 21.64 \mathrm{a}$ & ${ }^{N s} 21.69 \mathrm{a}$ & ${ }^{* *} 22.37 \mathrm{a}$ \\
Without Trichoderma & $19.48 \mathrm{~b}$ & $22.10 \mathrm{a}$ & $20.76 \mathrm{~b}$ \\
\hline
\end{tabular}

ANOVA significance at each level: ${ }^{\mathrm{NS}}$ not significant, $* *<0.01, * * *<0.001$. Mean values followed by the same letter within the same column are not significantly different according to the Tukey test at $p \leq 0.05$

Table 6. Effect of interaction between Trichoderma, hybrid, and substrate on the total soluble solids to titratable acidity ratio at three cluster levels

\begin{tabular}{lcccrcc}
\hline & \multicolumn{2}{c}{ Level 1 } & \multicolumn{2}{c}{ Level 2 } & \multicolumn{2}{c}{ Level 3 } \\
& With T & No T & With T & No T & With T & No T \\
\hline Cid & & \multicolumn{2}{c}{ Hybrids $\times$ Trichoderma } \\
Ramsés & ***23.96 a & $19.65 \mathrm{~b}$ & Ns23.08 a & $22.68 \mathrm{a}$ & Ns20.92 b & $20.05 \mathrm{~b}$ \\
\hline & $19.31 \mathrm{~b}$ & $19.35 \mathrm{~b}$ & $20.30 \mathrm{~b}$ & $21.51 \mathrm{ab}$ & $23.83 \mathrm{a}$ & $21.46 \mathrm{~b}$ \\
\hline River Sand & ${ }^{* * *} 19.78 \mathrm{~b}$ & $19.15 \mathrm{~b}$ & ${ }^{*} 21.25 \mathrm{a}$ & $23.47 \mathrm{a}$ & ${ }^{* * *} 22.56 \mathrm{~b}$ & $21.59 \mathrm{bc}$ \\
Tepezil & $20.10 \mathrm{~b}$ & $19.01 \mathrm{~b}$ & $21.81 \mathrm{a}$ & $21.88 \mathrm{a}$ & $18.69 \mathrm{~d}$ & $21.32 \mathrm{bc}$ \\
Tezontle & $25.04 \mathrm{a}$ & $20.28 \mathrm{~b}$ & $22.00 \mathrm{a}$ & $20.95 \mathrm{a}$ & $25.88 \mathrm{a}$ & $19.37 \mathrm{~cd}$ \\
\hline
\end{tabular}

ANOVA significance for the two interactions at each level: ${ }^{\mathrm{Ns}}$ not significant, $*<0.05, * * *<0.001$. Mean values followed by the same letter within the same column or row are not significantly different according to the Tukey test at $p \leq 0.05$; With $\mathrm{T}-$ with Trichoderma; No T - without Trichoderma

improve the flavour and aroma of food products. This increase in the ratio of sugars to acidity in fruits depends on the genetic constitution of the cultivar (Tigist et al., 2013), as demonstrated here, so the use of Trichoderma in the management of tomato crops could help to improve the flavour of tomato fruits.

The foliar application of Trichoderma increased the $\mathrm{pH}$ of fruits from levels 1 and 3 (Tab. 7). The treatment increased the $\mathrm{pH}$ of fruits of the Ramsés hybrid from levels 1 and 3 (by 4 and 2\%, respectively), and of the Cid hybrid only at level 3 (by 2\%) (Tab. 8). The foliar application of Trichoderma to the plants grown in the river sand and tezontle substrates increased the $\mathrm{pH}$ of fruits from levels 1 (by 5\%) and 3 (by 4\%), respectively. Without Trichoderma, the tepezil substrate contributed to a higher $\mathrm{pH}$ than tezontle (by 2\%) at level 3. A high $\mathrm{pH}$ value in juice indicates lower acidity and better flavour when consuming fruits fresh (Jones and Scott, 1983). As they mature, tomato fruits decrease in titratable acidity and increase in $\mathrm{pH}$ (Gautier et. al., 2008). This is because the organic acids are transformed into simple sugars in the vacuole, which are then used in the cellular respiration of the fruit (Klunklin and Savage, 2017). In this study, the application of Trichoderma increased the $\mathrm{pH}$ of the tomato fruits from clusters at different levels of the plant, which is in accordance with the decrease in TA. Merchán-Gaitán et al. (2014) report that
Trichoderma do not significantly modify the $\mathrm{pH}$ of strawberry fruit juice.

The foliar application of Trichoderma decreased the electrical conductivity (EC) at levels 1 and 3 (Tab. 7). The treatment increased EC in the Cid hybrid at level 2 (by 4\%); however, it decreased EC in the Cid and Ramsés hybrids at level 3 (by $4 \%$ in each) (Tab. 8). The application of Trichoderma to the plants grown in tezontle increased $\mathrm{EC}$ by $5 \%$ at level 2 , but decreased EC at level 3 by 9\%. Without Trichoderma, tepezil contributed to a higher EC than tezontle at level 2 (by 5\%), but at level 3 a higher EC was recorded for tezontle than tepezil (by $6 \%$ ). The internal conductivity of fruits depends on the integrity of the cell membrane and the decomposition of pectin (liberation of ions) (Dumville and Fry, 2003). The EC of tomato fruits decreases with increasing TSS (Palaniappan and Sastry, 1991). Therefore, Trichoderma possibly reduced the decomposition of pectin in fruits and decrease EC.

The foliar application of Trichoderma increased the percentage of juice $(\mathrm{PJ})$ at level 1 , but decreased PJ at levels 2 and 3 (Tab. 9). The treatment increased PJ in the Cid and Ramsés hybrids at level 1 (by 17 and 28\%, respectively). At the same time, the Cid hybrid had a higher PJ at level 1 than the Ramsés hybrid, with and without the application of Trichoderma (by 14 and 25\%, respectively) (Tab. 10). The application of Trichoderma reduced the 
Table 7. Effect of Trichoderma on $\mathrm{pH}$ and electrical conductivity $(\mathrm{mV})$ of juice from tomato fruits from clusters at different levels of the plant

\begin{tabular}{|c|c|c|c|}
\hline Treatment & Level 1 & Level 2 & Level 3 \\
\hline \multicolumn{4}{|c|}{$\mathrm{pH}$} \\
\hline With Trichoderma & ${ }^{* * *} 4.92 \mathrm{a}$ & Ns $4.94 \mathrm{a}$ & $* * 4.95 \mathrm{a}$ \\
\hline \multirow[t]{2}{*}{ Without Trichoderma } & $4.77 \mathrm{~b}$ & $4.93 \mathrm{a}$ & $4.86 \mathrm{~b}$ \\
\hline & & ctrical condu & \\
\hline With Trichoderma & ${ }^{*} 123.33 \mathrm{~b}$ & ${ }^{\mathrm{NS}} 121.94 \mathrm{a}$ & ${ }^{* * *} 122.00 \mathrm{~b}$ \\
\hline Without Trichoderma & $127.83 \mathrm{a}$ & $119.94 \mathrm{a}$ & $126.78 \mathrm{a}$ \\
\hline
\end{tabular}

ANOVA significance at each level: ${ }^{\mathrm{NS}}$ not significant, $*<0.05, * * *<0.001$. Mean values followed by the same letter within the same column are not significantly different according to the Tukey test at $p \leq 0.05$

Table 8. Effect of interaction between Trichoderma, hybrids, and substrates on $\mathrm{pH}$ and electrical conductivity at three different cluster levels

\begin{tabular}{|c|c|c|c|c|c|c|}
\hline & \multicolumn{2}{|c|}{ Level 1} & \multicolumn{2}{|c|}{ Level 2} & \multicolumn{2}{|c|}{ Level 3} \\
\hline & With T & No $T$ & With T & No $T$ & With T & No $T$ \\
\hline & \multicolumn{6}{|c|}{$\mathrm{pH}$} \\
\hline & \multicolumn{6}{|c|}{ Hybrids $\times$ Trichoderma } \\
\hline Cid & Ns4.92 a & $4.81 \mathrm{ab}$ & ${ }^{N S} 4.91 \mathrm{a}$ & $4.92 \mathrm{a}$ & ${ }^{N S} 4.94 \mathrm{a}$ & $4.85 \mathrm{~b}$ \\
\hline \multirow[t]{2}{*}{ Ramsés } & $4.92 \mathrm{a}$ & $4.73 \mathrm{~b}$ & $4.96 \mathrm{a}$ & $4.94 \mathrm{a}$ & $4.96 \mathrm{a}$ & $4.87 \mathrm{~b}$ \\
\hline & \multicolumn{6}{|c|}{ Substrates $\times$ Trichoderma } \\
\hline River sand & $\mathrm{NS}_{4.96 \mathrm{a}}$ & $4.73 \mathrm{~b}$ & Ns4.97 a & $4.98 \mathrm{a}$ & ${ }^{* * *} 4.95 \mathrm{ab}$ & $4.92 \mathrm{ab}$ \\
\hline Tepezil & $4.90 \mathrm{ab}$ & $4.72 \mathrm{~b}$ & $4.94 \mathrm{a}$ & $4.92 \mathrm{a}$ & $4.93 \mathrm{ab}$ & $4.87 \mathrm{~b}$ \\
\hline \multirow[t]{3}{*}{ Tezontle } & $4.89 \mathrm{ab}$ & $4.87 \mathrm{ab}$ & $4.91 \mathrm{a}$ & $4.90 \mathrm{a}$ & $4.97 \mathrm{a}$ & $4.80 \mathrm{c}$ \\
\hline & \multicolumn{6}{|c|}{ Electrical conductivity } \\
\hline & \multicolumn{6}{|c|}{ Hybrids $\times$ Trichoderma } \\
\hline Cid & ${ }^{\mathrm{NS}} 123.22 \mathrm{a}$ & $129.00 \mathrm{a}$ & ${ }^{*} 122.89 \mathrm{a}$ & $118.11 \mathrm{~b}$ & ${ }^{\mathrm{NS}} 123.00 \mathrm{~b}$ & $127.89 \mathrm{a}$ \\
\hline \multirow[t]{2}{*}{ Ramsés } & $123.44 \mathrm{a}$ & $126.67 \mathrm{a}$ & $121.00 \mathrm{ab}$ & $121.78 \mathrm{ab}$ & $121.00 \mathrm{~b}$ & $125.67 \mathrm{a}$ \\
\hline & \multicolumn{6}{|c|}{ Substrates $\times$ Trichoderma } \\
\hline River sand & ${ }^{\mathrm{NS}} 120.33 \mathrm{~b}$ & $126.00 \mathrm{ab}$ & ${ }^{*} 121.00 \mathrm{ab}$ & $119.83 \mathrm{ab}$ & ${ }^{* * *} 122.17 \mathrm{bc}$ & $123.17 \mathrm{bc}$ \\
\hline Tepezil & $125.00 \mathrm{ab}$ & $133.00 \mathrm{a}$ & $121.50 \mathrm{ab}$ & $123.00 \mathrm{a}$ & $123.00 \mathrm{bc}$ & $125.17 \mathrm{~b}$ \\
\hline Tezontle & $124.67 \mathrm{ab}$ & $124.50 \mathrm{ab}$ & $123.33 \mathrm{a}$ & $117.00 \mathrm{~b}$ & $120.83 \mathrm{c}$ & $132.00 \mathrm{a}$ \\
\hline
\end{tabular}

ANOVA significance for the two interactions at each level: ${ }^{\mathrm{NS}}$ not significant, $*<0.05, * * *<0.001$. Mean values followed by the same letter within the same column or row are not significantly different according to the Tukey test at $p \leq 0.05$; With $\mathrm{T}-$ with Trichoderma; No T - without Trichoderma

PJ of the Ramsés and Cid hybrids at level 2 (by 7 and $8 \%$, respectively) and level 3 (by 7 and $2 \%$, respectively). The Ramsés hybrid had a higher PJ than the Cid hybrid, with and without the Trichoderma application, at level 2 (by 8 and 7\%, respectively), and without Trichoderma at level 3 (by 7\%). The foliar application of Trichoderma to the plants grown in river sand, tepezil and tezontle increased the PJ of fruits from level 1 (by 11, 23 and $36 \%$, respectively). The river sand contributed to the highest PJ at level 1, with and without Trichoderma, compared to the other substrates. At level 2, the application of Trichoderma to the plants grown in river sand and tezontle decreased PJ (by 8 and

Table 9. Effect of foliar application of Trichoderma on the percent juice of fruits from different cluster levels of the plant

\begin{tabular}{lccc}
\hline Treatment & Level 1 & Level 2 & Level 3 \\
\hline With Trichoderma & ${ }^{* * *} 74.80 \mathrm{a}$ & ${ }^{* * *} 67.93 \mathrm{~b}$ & ${ }^{* * *} 65.43 \mathrm{~b}$ \\
Without Trichoderma & $61.27 \mathrm{~b}$ & $73.08 \mathrm{a}$ & $68.43 \mathrm{a}$ \\
\hline
\end{tabular}

ANOVA significance at each level: $* * *<0.001$. Mean values followed by the same letter within the same column are not significantly different according to the Tukey test at $p \leq 0.05$ 
Table 10. Effect of interaction between Trichoderma, hybrid, and substrate on the percent juice at three cluster levels

\begin{tabular}{lcccccc}
\hline & \multicolumn{2}{c}{ Level 1 } & \multicolumn{2}{c}{ Level 2 } & \multicolumn{2}{c}{ Level 3 } \\
& With T & Without T & With T & Without T & With T & Without T \\
\hline Cid & ${ }^{* * *} 79.67 \mathrm{a}$ & $68.00 \mathrm{c}$ & ${ }^{\text {Ns }} 65.33 \mathrm{c}$ & $70.60 \mathrm{~b}$ & $* * * 65.10 \mathrm{c}$ & $66.23 \mathrm{~b}$ \\
Ramsés & $69.93 \mathrm{~b}$ & $54.53 \mathrm{~d}$ & $70.53 \mathrm{~b}$ & $75.57 \mathrm{a}$ & $65.77 \mathrm{bc}$ & $70.63 \mathrm{a}$ \\
\hline & \multicolumn{7}{c}{ Substrates $\times$ Trichoderma } \\
\hline River Sand & ${ }^{* * * *} 81.70 \mathrm{a}$ & $73.55 \mathrm{c}$ & ${ }^{* * * *} 64.20 \mathrm{e}$ & $69.60 \mathrm{c}$ & $* * * 68.35 \mathrm{~b}$ & $69.12 \mathrm{~b}$ \\
Tepezil & $65.70 \mathrm{~d}$ & $53.50 \mathrm{f}$ & $67.40 \mathrm{~d}$ & $67.35 \mathrm{~d}$ & $66.35 \mathrm{c}$ & $70.43 \mathrm{a}$ \\
Tezontle & $77.00 \mathrm{~b}$ & $56.75 \mathrm{e}$ & $72.20 \mathrm{~b}$ & $82.30 \mathrm{a}$ & $61.60 \mathrm{~d}$ & $65.75 \mathrm{c}$ \\
\hline
\end{tabular}

ANOVA significance for the two interactions at each level: ${ }^{\text {NS }}$ not significant, $* * *<0.001$. Mean values followed by the same letter within the same column or row are not significantly different according to the Tukey test at $p \leq 0.05$; With $\mathrm{T}-$ with Trichoderma; No T - without Trichoderma

$12 \%$, respectively); tezontle contributed to a higher PJ, with and without Trichoderma, compared to the other substrates. At level 3, tepezil and tezontle decreased PJ with the application of Trichoderma (each by $6 \%$ ). The juiciness of the tomato fruit is a very important internal attribute for the end consumer (Oltman et al., 2014). The increase in the juiciness of fruits is due to the activity of the enzyme polygalacturonase, which produces low-molecular weight pectins (Illera et al., 2018). Juiciness also depends on the activity of the enzyme pectin methylesterase, which inhibits polygalacturonase and produces high-molecular weight pectins that congeal in water (Wormit and Usadel, 2018). The application of Trichoderma possibly interfered in the methylation of polygalacturonase (Mohamed et al., 2003) and reduce the PJ at levels 2 and 3.

The foliar application of Trichoderma increased the colour purity (CHROMA) and decreased the hue angle (HUE) at level 2 (Tab. 11). The treatment decreased the HUE of the Cid hybrid at level 2 by $5 \%$, but had no different effects among the substrates evaluated (Tab. 12). There is a large degree of genetic variation in tomato fruit colour (Heuvelink, 2018). The vibrant red colour is due to the presence and synthesis of lycopene (White, 2002; Barrett and Anthon, 2008); a low positive value of HUE indicates a redder colour. HUE is considered an indicator of lycopene content, that is, the lower the HUE value, the higher the lycopene content (Thompson et al., 2000). In this study, there is no clear tendency of a decrease in HUE caused by Trichoderma; it only decreased at level 2 . Accordingly, the application of Trichoderma does not affect the colour of tomato fruits.

\section{CONCLUSIONS}

The foliar application of Trichoderma improved the ratio of total soluble solids to titratable acidity of tomato fruits at different cluster levels, which was mainly due to the decrease in titratable acidity. The decrease in titratable acidity is in accordance with the increase in the $\mathrm{pH}$ of the fruits. The treatment also positively affected the electrical conductivity of the fruits. The effect of Trichoderma application at different levels of fruit clusters varied depending on

Table 11. Effect of Trichoderma on colour parameters at three levels of fruit clusters of the plan

\begin{tabular}{lccc}
\hline Treatment & Level 1 & Level 2 & Level 3 \\
\hline With Trichoderma & & HUE & Ns41.60 a \\
Without Trichoderma & Ns39.33 a & ${ }^{* * 3} 39.12 \mathrm{~b}$ & $41.37 \mathrm{a}$ \\
\hline & $38.94 \mathrm{a}$ & $40.47 \mathrm{a}$ & \\
\hline With Trichoderma & & CHROMA & Ns34.25 a \\
Without Trichoderma & Ns36.35 a & ${ }^{* *} 36.95 \mathrm{a}$ & $33.94 \mathrm{a}$ \\
\hline & $36.52 \mathrm{a}$ & $35.74 \mathrm{~b}$ & Ns37.65 a \\
\hline With Trichoderma & & $\mathrm{L}$ & $37.08 \mathrm{a}$ \\
\hline Without Trichoderma & Ns37.17 a & Ns37.71 a & $37.24 \mathrm{a}$ \\
\hline
\end{tabular}

ANOVA significance at each level: Ns not significant, $* *<0.01$. Mean values followed by the same letter within the same column are not significantly different according to the Tukey test at $p \leq 0.05$. HUE - hue angle; CHROMA - colour purity; L - luminosity 
Table 12. Effect of interaction between Trichoderma, hybrid, and substrate on colour parameters at three levels of fruit clusters

\begin{tabular}{|c|c|c|c|c|c|c|}
\hline & \multicolumn{3}{|c|}{ With Trichoderma } & \multicolumn{3}{|c|}{ Without Trichoderma } \\
\hline & HUE & CHROMA & $\mathrm{L}$ & HUE & CHROMA & $\mathrm{L}$ \\
\hline & \multicolumn{6}{|c|}{ Level 1} \\
\hline & \multicolumn{6}{|c|}{ Hybrids $\times$ Trichoderma } \\
\hline Cid & Ns39.60 a & Ns36.93 a & Ns37.35 a & $39.03 \mathrm{a}$ & $36.48 \mathrm{a}$ & $37.17 \mathrm{a}$ \\
\hline \multirow[t]{2}{*}{ Ramsés } & $39.05 \mathrm{a}$ & $35.77 \mathrm{a}$ & $36.98 \mathrm{a}$ & $38.35 \mathrm{a}$ & $36.56 \mathrm{a}$ & $35.66 \mathrm{a}$ \\
\hline & \multicolumn{6}{|c|}{ Substrates $\times$ Trichoderma } \\
\hline River Sand & Ns39.82 a & ${ }^{\mathrm{N}} 36.39 \mathrm{a}$ & Ns37.36 a & $39.10 \mathrm{a}$ & $36.66 \mathrm{a}$ & $35.04 \mathrm{a}$ \\
\hline Tepezil & $38.56 \mathrm{a}$ & $36.50 \mathrm{a}$ & 36.93 a & $38.55 \mathrm{a}$ & $37.27 \mathrm{a}$ & $37.36 \mathrm{a}$ \\
\hline \multirow[t]{3}{*}{ Tezontle } & $39.61 \mathrm{a}$ & $36.17 \mathrm{a}$ & $37.21 \mathrm{a}$ & $39.17 \mathrm{a}$ & $35.63 \mathrm{a}$ & $36.84 \mathrm{a}$ \\
\hline & \multicolumn{6}{|c|}{ Level 2} \\
\hline & \multicolumn{6}{|c|}{ Hybrids $\times$ Trichoderma } \\
\hline Cid & $* 38.38 \mathrm{~b}$ & Ns36.30 ab & Ns37.26 a & $40.78 \mathrm{a}$ & $35.16 \mathrm{~b}$ & $37.22 \mathrm{a}$ \\
\hline \multirow[t]{2}{*}{ Ramsés } & $39.86 \mathrm{ab}$ & $37.60 \mathrm{a}$ & $38.15 \mathrm{a}$ & $40.17 \mathrm{a}$ & $36.32 \mathrm{ab}$ & $37.26 \mathrm{a}$ \\
\hline & \multicolumn{6}{|c|}{ Substrates $\times$ Trichoderma } \\
\hline River Sand & Ns37.92 b & Ns37.65 a & ${ }^{\mathrm{N}} 37.66 \mathrm{a}$ & $40.24 \mathrm{ab}$ & $36.93 \mathrm{ab}$ & $37.40 \mathrm{a}$ \\
\hline Tepezil & $40.26 \mathrm{ab}$ & $36.24 \mathrm{ab}$ & $37.71 \mathrm{a}$ & $41.24 \mathrm{a}$ & $35.50 \mathrm{ab}$ & $37.61 \mathrm{a}$ \\
\hline \multirow[t]{3}{*}{ Tezontle } & $39.18 \mathrm{ab}$ & $36.97 \mathrm{ab}$ & $37.76 \mathrm{a}$ & $39.93 \mathrm{ab}$ & $34.79 \mathrm{~b}$ & $36.70 \mathrm{a}$ \\
\hline & \multicolumn{6}{|c|}{ Level 3} \\
\hline & \multicolumn{6}{|c|}{ Hybrids $\times$ Trichoderma } \\
\hline Cid & *40.92 a & Ns34.47 a & ${ }^{N s} 37.65 \mathrm{a}$ & $42.45 \mathrm{a}$ & $34.92 \mathrm{a}$ & $37.42 \mathrm{a}$ \\
\hline \multirow[t]{2}{*}{ Ramsés } & $42.29 \mathrm{a}$ & $34.03 \mathrm{a}$ & $37.64 \mathrm{a}$ & $40.29 \mathrm{a}$ & $32.95 \mathrm{a}$ & $36.74 \mathrm{a}$ \\
\hline & \multicolumn{6}{|c|}{ Substrates $\times$ Trichoderma } \\
\hline River Sand & Ns41.59 a & ${ }^{\mathrm{N}} 33.88 \mathrm{a}$ & ${ }^{\mathrm{N}} 37.23 \mathrm{a}$ & $40.38 \mathrm{a}$ & $33.47 \mathrm{a}$ & $37.10 \mathrm{a}$ \\
\hline Tepezil & $41.73 \mathrm{a}$ & $35.67 \mathrm{a}$ & $38.54 \mathrm{a}$ & $41.34 \mathrm{a}$ & $33.89 \mathrm{a}$ & $36.70 \mathrm{a}$ \\
\hline Tezontle & $41.48 \mathrm{a}$ & $33.20 \mathrm{a}$ & $37.17 \mathrm{a}$ & $42.40 \mathrm{a}$ & $34.46 \mathrm{a}$ & $37.45 \mathrm{a}$ \\
\hline
\end{tabular}

ANOVA significance for the two interactions at each level: Ns not significant, $*<0.05$. Mean values followed by the same letter within the same column or row are not significantly different according to the Tukey test at $p \leq 0.05$. HUE - hue angle; CHROMA - colour purity; L - luminosity

the hybrid and substrate evaluated. The Cid hybrid and the tezontle substrate presented the best ratio of total soluble solids to titratable acidity. The river sand substrate contributed to the highest percent juice. Foliar application of Trichoderma to tomato plants improves the quality of the fruits and should be considered in crop management programmes.

\section{ACKNOWLEDGEMENT}

The authors thank Dr. Vladimir Sánchez López for providing detailed information on the methodology for preparing the liquid biological preparation of Trichoderma.

\section{FUNDING}

This research was supported by the professorate improvement program (PROMEP, acronym in Spanish) through project PROMEP/103.5/12/7959 "Evaluation of different types of tomato production
(Solanum lycopersicum L.) under the protected agriculture scheme in Loma Bonita, Oaxaca".

\section{AUTHOR CONTRIBUTIONS}

R.E.P.T. and H.H.H. - conceived and designed the experiments; A.R.R.S. - performed the data analysis; A.G.B.O. and L.A.P.B. - performed the analysis of laboratory and field experiments; J.A.Y.T. and G.D.F. - contributed reagents and materials. All of the authors were responsible for manuscript writing.

\section{CONFLICT OF INTEREST}

Authors declare no conflict of interest.

\section{REFERENCES}

AOAC, 2000. Official Methods of Analysis of AOAC International ( $17^{\text {th }}$ edition). Association of Official 
Analysis Chemists International, Methods No. 2-66, AOAC, Washington, DC.

Bal U., Altintas S., 2006. Effects of Trichoderma harzianum on the yield and fruit quality of tomato plants (Lycopersicon esculentum) grown in an unheated greenhouse. Aust. J. Exp. Agr. 46(1), 131136.

Barrett D.M., Anthon G.E., 2008. Color quality of tomato products. In: Color Quality of Fresh and Processed Foods. C.A. Culver and R.E. Wrolstad (Eds), American Chemical Society, Washington, DC, USA, 131-139.

Bertin N., GÉnARd M., 2018. Tomato quality as influenced by preharvest factors. Sci. Hortic. 233, 264-276.

Biais B., Benard C., Beauvoit B., Colombi S., Prodhomme D., Menard G., et AL., 2014. Remarkable reproducibility of enzyme activity profiles in tomato fruits grown under contrasting environments provides a roadmap for studies of fruit metabolism. Plant Physiol. 164(3), 1204-1221.

CAusse M., 2002. QTL analysis of fruit quality in fresh market tomato: a few chromosome regions control the variation of sensory and instrumental traits. J. Exp. Bot. 53, 2089-2098.

Chen M., Jiang Q., Yin X.R., Lin Q., Chen J.Y., Allan A.C., ET AL., 2012. Effect of hot air treatment on organic acid- and sugar-metabolism in Ponkan (Citrus reticulata) fruit. Sci. Hortic. 147, 118-125.

Davies J.N., Hobson G.E., 1981. The constituents of tomato fruit - the influence of environment, nutrition, and genotype. Crit. Rev. Food Sci. Nutr. 15(3), 205280.

Dumville J.C., Fry S.C., 2003. Solubilisation of tomato fruit pectins by ascorbate: a possible non-enzymic mechanism of fruit softening. Planta 217(6), 951961.

FAOSTAT, 2015. Food and Agriculture Organization of the United Nations. Available online at www.fao.org/ faostat/; cited on 15 Jun 2019.

Figàs M.R., Prohens J., Raigón M.D., Fita A., García-Martínez M.D., Casanova C., ET AL., 2015. Characterization of composition traits related to organoleptic and functional quality for the differentiation, selection and enhancement of local varieties of tomato from different cultivar groups. Food Chem. 187, 517-524.

Gautier H., Diakou-Verdin V., Bénard C., Reich M., Buret M., Bourgaud F., Et AL., 2008. How does tomato quality (sugar, acid, and nutritional quality) vary with ripening stage, temperature, and irradiance? J. Agric. Food Chem. 56(4), 1241-1250.

Génard M., Memmah M.M., Quilot-Turion B., Vercambre G., Baldazzi V., Le Bot J., 2016. Process-based simulation models are essential tools for virtual profiling and design of ideotypes: Example of fruit and root. In: Crop Systems Biology. X. Yin and P. Struik (Eds), Springer, Cham, Switzerland, 83104.

Heredia A., Barrera C., Andrés A., 2007. Drying of cherry tomato by a combination of different dehydration techniques. Comparison of kinetics and other related properties. J. Food Eng. 80(1), 111-118.

Heuvelink E., 2018. Tomatoes. CABI, Boston, MA, USA.

Illera A.E., Sanz M.T., Trigueros E., Beltrán S., Melgosa R., 2018. Effect of high pressure carbon dioxide on tomato juice: Inactivation kinetics of pectin methylesterase and polygalacturonase and determination of other quality parameters. J. Food Eng. 239, 64-71.

InFoStat, 2018. Statistical Software. Available online at www.infostat.com.ar; cited on 28 Sep 2019.

Jones R.A., ScotT S.J., 1983. Improvement of tomato flavor by genetically increasing sugar and acid contents. Euphytica 32(3), 845-855.

Keswani C., Mishra S., Sarma B.K., Singh S.P., Singh H.B., 2014. Unraveling the efficient applications of secondary metabolites of various Trichoderma spp. Appl. Microbiol. Biotechnol. 98(2), 533-544.

Klunklin W., Savage G., 2017. Effect on quality characteristics of tomatoes grown under well-watered and drought stress conditions. Foods 6, 56.

López-Bucio J., Pelagio-Flores R., HerreraEstrella A., 2015. Trichoderma as biostimulant: exploiting the multilevel properties of a plant beneficial fungus. Sci. Hortic. 196, 109-123.

Merchán-Gaitán J.V., Ferrucho R.L., ÁlvarezHerrera J.G., 2014. Effect of two Trichoderma strains on Botrytis cinerea control and fruit quality for the strawberry (Fragaria sp.). Rev. Colomb. Cienc. Hortic. 8(1), 44-56.

Mohamed S.A., Christensen T.M.I.E., Mikkelsen J.D., 2003. New polygalacturonases from Trichoderma reesei: characterization and their specificities to partially methylated and acetylated pectins. Carbohydr. Res. 338(6), 515-524.

Molla A.H., Manjurul Haque M., Amdadul Haque M., Ilias G.N.M., 2012. Trichoderma-enriched biofertilizer enhances production and nutritional quality of tomato (Lycopersicon esculentum Mill.) and minimizes NPK fertilizer use. Agric. Res. 1(3), 265-272.

Nzanza B., Marais D., Soundy P., 2012. Response of tomato (Solanum lycopersicum L.) to nursery inoculation with Trichoderma harzianum and arbuscular mycorrhizal fungi under field conditions. Acta Agric. Scand. B Soil Plant Sci. 62(3), 209-215.

Oltman A.E., Jervis S.M., Drake M.A., 2014. Consumer attitudes and preferences for fresh market tomatoes. J. Food Sci. 79(10), S2091-S2097.

PALANIAPPAN S., SASTRY S.K., 1991. Electrical conductivity of selected juices: influences of temperature, solids content, applied voltage, and particle size. J. Food Process Eng. 14(4), 247-260. 
Pascale A., Vinale F., Manganiello G., Nigro M., Lanzuise S., RuOcCo M., ET AL., 2017. Trichoderma and its secondary metabolites improve yield and quality of grapes. Crop Prot. 92, 176-181.

Ruiz-Cisneros M.F., Ornelas-Paz J.D.J., OlivasOrozco G.I., Acosta-MuñIz C.H., SepúlvedaAhumada D.R., PÉrez-Corral D.A., ET AL., 2018. Effect of Trichoderma spp. and phytopathogenic fungi on plant growth and tomato fruit quality. Mex. J. Phytopathol. 36, 444-456.

Shoresh M., Harman G.E., 2008. The molecular basis of shoot responses of maize seedlings to Trichoderma harzianum T22 inoculation of the root: a proteomic approach. Plant Physiol. 147(4), 2147-2163.

SteINER A.A., 1961. A universal method for preparing nutrient solutions of a certain desired composition. Plant Soil 15(2), 134-154.

Thompson K.A., Marshall M.R., Sims C.A., Wei C.I., SARgent S.A., Scott J.W., 2000. Cultivar, maturity, and heat treatment on lycopene content in tomatoes. J. Food Sci. 65(5), 791-795.

Tigist M., WorkneH T.S., Woldetsadik K., 2013. Effects of variety on the quality of tomato stored under ambient conditions. J. Food Sci. Technol. 50(3), 477-486.

USDA, 1991. United States Standards for Grades of Fresh Tomatoes. Available from: www.ams.usda.gov/sites/ default/files/media/Tomato_Standard\%5B1\%5D. pdf; cited on 21 Jun 2019.

Valero D., Serrano M., 2010. Postharvest Biology and Technology for Preserving Fruit Quality. CRC Press, Boca Raton, FL, USA.

White P.J., 2002. Recent advances in fruit development and ripening: an overview. J. Exp. Bot. 53(377), 1995-2000.

Winsor G.W., Davies J.N., Massey D.M., 1962. Composition of tomato fruit. III.- Juices from whole fruit and locules at different stages of ripeness. J. Sci. Food Agric. 13(2), 108-115.

Wormit A., Usadel B., 2018. The multifaceted role of pectin methylesterase inhibitors (PMEIs). Int. J. Mol. Sci. 19(10), 1-19.

Received July 10, 2019; accepted October 10, 2019 